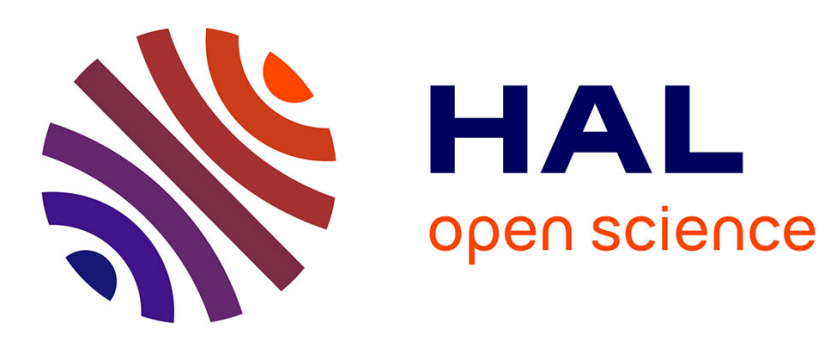

\title{
On the rapid manufacturing process of functional 3D printed sand molds
}

Saptarshee Mitra, Antonio Rodríguez de Castro, Mohamed El Mansori

\section{To cite this version:}

Saptarshee Mitra, Antonio Rodríguez de Castro, Mohamed El Mansori. On the rapid manufacturing process of functional 3D printed sand molds. Journal of Manufacturing Processes, 2019, 42, pp.202212. 10.1016/j.jmapro.2019.04.034 . hal-02317685

\section{HAL Id: hal-02317685 \\ https://hal.science/hal-02317685}

Submitted on 16 Oct 2019

HAL is a multi-disciplinary open access archive for the deposit and dissemination of scientific research documents, whether they are published or not. The documents may come from teaching and research institutions in France or abroad, or from public or private research centers.
L'archive ouverte pluridisciplinaire HAL, est destinée au dépôt et à la diffusion de documents scientifiques de niveau recherche, publiés ou non, émanant des établissements d'enseignement et de recherche français ou étrangers, des laboratoires publics ou privés. 
$4{ }^{1}$ Laboratoire MSMP - EA7350, Arts et Métiers ParisTech, 2 Cours des Arts et Métiers,

${ }^{2}$ Laboratoire MSMP - EA7350, Arts et Métiers ParisTech, Rue Saint Dominique, 51006

7 Châlons-en-Champagne, France

8

${ }^{3}$ Texas A\&M Engineering Experiment Station, College Station, TX 77843, USA

\section{Abstract}

3D printing sand mold technology offers an opportunity for the foundry industry to rethink old casting approaches and to revive the manufacturing approach using computer models. One of the major concerns in sand molding using 3D printing is the functional characterization of the 3D printed molds as its mechanical and mass transport properties. This research paper discusses the effects of binder content on the mechanical strength and the permeability of 3DP sand molds at different curing conditions. The local permeability of the 3DP specimen was measured as a function of the injection flow rate in order to quantify the inertial pressure effects. The mechanical strength of the 3DP sand molds was characterized using traditional three-point bending strength measurements. The results show that the mechanical strength of the printed molds is deeply dependent on the amount of binder and the curing process. The 3PB strength was found to increase when cured at $100{ }^{\circ} \mathrm{C}$ and decrease when cured at $200{ }^{\circ} \mathrm{C}$ 
for all binder contents. The 3PB strength attains its maximum when cured at $100{ }^{\circ} \mathrm{C}$ for 2 hours for all binder content. In contrast, no significant effect of the amount of binder on the initial permeability of the samples before curing was observed within the functional range of binder mass fraction (1.02 to $1.98 \%)$. Maximum permeability is attained at the same conditions as the 3PB strength. Therefore, the mechanical strength of the sample can be optimized within the investigated range of binder contents without resulting in any significant decrease in permeability.

Keywords: Additive manufacturing; 3D Printing; Mold characterization; Sand casting; Threepoint bending strength; Permeability.

\section{Introduction}

Sand casting is a cost-effective method adopted in the production of metallic parts and is an excellent solution to manufacture low-to-medium runs of parts meeting standard dimensional requirements. Three-dimensional printing (3DP) of sand molds uses Powder Binder Jetting (PBJ) technology and overcomes some of the issues commonly encountered in traditional production methods. Indeed, 3DP technology allows rapid production of high-quality sand molds with complex geometry as required in many casting applications [1,2], and ensures optimized design freedom for any castable alloys [1-3]. The layer-based Three-Dimensional Printing (3DP) technology is an Additive Manufacturing (AM) technique which was invented at MIT to produce 3D parts directly from computer-aided designs (CAD) [4-7] This technology has been fully recognized as one of the most promising technologies for the 
production of casting sand molds. Among the available AM techniques, the powder-based ink-jet 3D printing, which is based on the basis of a chemical reaction between silica sand powder and an acidic binder, is widely used to manufacture sand molds. An extensive literature review in this area of research [8] and a few studies on the relationship between the properties of the $3 \mathrm{D}$ printed specimen and processing parameters $[9,10]$ have been recently published.

Foundries encounter a wide variation in the physical properties of the 3DP resin-bonded sand molds, e.g. three-point bending (3PB) strength and permeability, which depend on certain variables such as moisture and binder content. Indeed, greater binder contents generally result in higher values of mechanical strength, but also in more gas being produced during metal casting. Also, an excessively high amount of binder makes the 3DP sand mold too rigid impeding proper expansion and giving rise to hot tearing defects and high residual stresses $[11,12]$. In contrast, low binder amounts reduce the off-gassing but affect negatively the mechanical strength, which can lead to penetration of the molten metal into the large intersand interstices producing enlarged, rough surfaces on the casting. On the other hand, the process of mold filling requires consideration of air evacuation from the mold cavity driven by the compression of the gas by the melt. In particular, the melt can entrap air and other gases in the mold cavity, which is favored by turbulent filling. Consequently, it is necessary to evacuate the gas in an efficient manner in order to obtain a sound casting product with a minimum of defects. For these reasons, the success of this novel technology is strongly conditioned by the production of sufficiently permeable sand molds with convenient mechanical strength for their manipulation. 
3DP furan resin-bonded sand is widely used in casting due to the high dimensional precision and mechanical strength of the produced parts. Furan Binder (FNB) is composed of an acid catalyst (Toluene Sulfonic acid) and furfuryl alcohol which generates a 3-dimensional polymer chain network (furan resin bridges) through acid-hardening reaction, polymerization, and condensation. The polymer bridges ( $\mathrm{H}-\mathrm{C}$ bonds) observed in furan resin bonded sand mold provide extra cohesion and strength to the silica sand particles, which is necessary in order to retain the shape of 3D printed sand molds when in contact with the melt. The furan binder condensation reaction produces water (dehydration), which tends to slow down the rate of curing and hence affects the strength and permeability $[13,14]$ of the molds. The recent research shows that there are many possible factors affecting the quality of 3DP sand molds, including furan resin binder content, curing temperature, curing time, types of base sand and sand grain size $[10,15-20]$. All these works point out the high variability of the 3DP sand molds.

The effects of curing time and temperature on permeability and mechanical strength using ZCast 501 powder and Zb56 resin binder system of the ZCorporation were investigated by other researchers [21]. The effects of curing time and temperature on permeability and mechanical strength using ExOne 3D printed sand mold was also investigated [10], where it was shown that the permeability decreased with increase in curing temperature. In the latter work, a mathematical model was proposed to predict an optimal curing time and temperature for both permeability and compressive strength. Also, the curing cycle of parts fabricated with ZCAST ${ }^{\circledR}$ was optimized by taking into account the potential casting defects due to offgassing of volatile binder components [22,23]. These works showed that using higher amounts of binder $(8-9 \%)$ than the standard values in casting sand $(1.4 \%)$ results in more offgassing and incomplete filling of the mold $[8,22,23]$. The same aspects were also studied in 
95 the case of an ExOne ${ }^{\mathrm{TM}} 3 \mathrm{D}$ printer, finding that the specimens had high mechanical strength ( 1.3 MPa) with less amount of binder than in ZCAST system, due to the well-controlled distribution of silica sand and furan resin binder [23]. Recommendations on the orientation and position of the samples in the job box can also be found in the recent literature in order to minimize the anisotropic behavior of the molds produced with this technology [9].

ExOne S-Print is one of the latest machines for 3D printed porous sand molds using furan binder system, and it requires curing (heat treatment) to remove the byproduct (water) from the polycondensation (polymerization + condensation) of the furfuryl alcohol based monomers (the furan resin), from the mold. This evolution of binder affects both the mechanical and mass transport properties of the mold hence results in altered gas permeability. In particular, the mass flow rate by which the air is evacuated from the molds is directly related to pore size and binder percentage (microscopic characteristic length). Therefore, there is a vital need for a suitable method for characterizing the permeability and its relation to the curing temperature and time. The evolution of permeability and mechanical strength of the 3DP sand molds during the curing stage was studied in a recent work using traditional characterization methods for a unique value of binder content [10]. However, the effects of binder content on permeability and 3PB strength have still not been studied to the best of our knowledge. Such effects are expected to play a crucial role in the functionality of the casted parts for the above-mentioned reasons. To fill this gap, the present study focuses on the effect of binder mass fraction on permeability and mechanical strength of printed molds for different curing temperatures and times. 


\section{Theoretical background}

Three-point bending (3PB) tests are commonly used to characterize the mechanical strength of brittle materials. These tests are comparatively easy to set up and interpret and are usually performed on a rectangular bar, which is positioned over two roller pin supports while the load is applied via a third roller pin typically mounted halfway between the pin supports. The 3PB bending stress is calculated using the measured load from Eq. 1:

$$
\sigma=\mathrm{F} \times \frac{3 \mathrm{l}}{2 \mathrm{bd} \mathrm{d}^{2}}
$$

where $\mathrm{F}$ is the load at the middle section of the 3DP rectangular bar, 1 is the length between the support span, $b$ is the width of 3DP test bar and $d$ is the thickness of the 3DP tested sample.

Permeability can be defined as the ability of a porous medium to allow the fluids to pass through it when driven by a pressure gradient. In the particular case of casting sands, the standard method recommended by the American Foundry Society (AFS) consists in determining gas permeability (GP), which is extensively used in foundry industries [24]. In spite of the key advantages provided by the simplicity and rapidity of this traditional method, GP is not an intrinsic porous-medium property and does not have permeability units $\left[\mathrm{m}^{2}\right]$. Indeed, GP depends on the dynamic shear viscosity of the injected fluid, which increases with temperature and generates higher pressure losses at higher temperatures for similar injection flow rates. Also, the standard method does not take into account the inertial pressure drops 
$\nabla \mathrm{P}=\frac{\mu}{\mathrm{K}} \frac{\mathrm{Q}_{\mathrm{v}}}{\mathrm{S}}$ present work.

and compressibility of the fluid. Consequently, the obtained permeability value is not accurate when the pressure gradient within the interstices of the sand is moderate or high. Furthermore, usual GP characterization is frequently based on a unique-point measurement, so the result is strongly influenced by experimental uncertainty. For these reasons, a rigorous method aiming to improve the accuracy of permeability measurements in 3DP molds will be used in the

In the case of unconsolidated granular media as 3DP sand molds, permeability mainly depends on the particle size distribution of the solids forming the bed, their shape, the liquid saturation of the pore interstices and the packing structure (i.e. bed bulk porosity). When dealing with casting processes, the pressure gradient is generated by the metallostatic pressure during filling of the mold (to which an external pressure can be added) and the shrinkage of the solidified alloy during cooling. Darcy's law (Eq. 2) is widely used to model the laminar steady flow of Newtonian fluids through porous media (e.g. sand molds). This law relates the volumetric flow rate to the pressure gradient through the viscosity of the fluid and the permeability of the porous material.

In the preceding equation, $Q_{v}$ is the volumetric flow rate, $S$ is the cross-sectional area, $\mu$ is the dynamic shear viscosity of the injected fluid, $\nabla \mathrm{P}=\frac{\Delta \mathrm{P}}{\mathrm{L}}$ is the pressure gradient and $\Delta \mathrm{P}$ is the pressure drop throughout a porous sample of length $\mathrm{L}$ and intrinsic permeability $\mathrm{K}$. In unidirectional flow, $\mathrm{K}$ is usually measured by injecting fluid with known viscosity through a 
sample of the investigated medium of known dimensions. During the tests, either $\mathrm{Q}_{\mathrm{v}}$ or $\Delta \mathrm{P}$ is imposed and the other magnitude is measured.

The value of $\mathrm{K}$ may be overestimated when performing measurements with gases at very low flow rates in porous media with low permeability. This is caused by wall-slip of the gas flow and is known as Klinkenberg effect [25,26]. Klinkenberg effect depends on the relative size of the gas molecule with respect to the diameters of the pore, becoming significant only when pore diameter is close to the mean free path of gas molecules. This is not the case of commonly used casting sands, which exhibit high permeability levels. However, special attention should be paid to the measurements performed at medium-to-high values of pressure gradient, due to inertial effects which result in extra pressure losses that are not taken into account by Darcy's law. Indeed, Darcy's law only applies to creeping flow in which inertial forces are negligible compared to viscous forces [27-30]. Nonlinearity of fluid flow stems from inertial pressure losses generated by the repeated accelerations and decelerations due to rapid changes in flow velocity and direction along the flow path. Both theoretical and empirical models taking into account the extra pressure losses due to inertial effects were presented in the literature [31].

Forchheimer's empirical law [32] is commonly used to model the nonlinear behavior associated to inertial regime through addition of a quadratic flow rate term to Darcy's law: 


$$
\nabla \mathrm{P}=\frac{\Delta \mathrm{P}}{\mathrm{L}}=\frac{\mu}{\mathrm{K}} \frac{\mathrm{Q}_{\mathrm{V}}}{\mathrm{S}}+\rho \beta\left(\frac{\mathrm{Q}_{\mathrm{v}}}{\mathrm{S}}\right)^{2}
$$

181 with $\nabla \mathrm{P}=\frac{\Delta \mathrm{P}}{\mathrm{L}}=\frac{\mathrm{P}_{\mathrm{i}}-\mathrm{P}_{\mathrm{o}}}{\mathrm{L}}, \mathrm{P}_{\mathrm{i}}$ being the absolute pressure at the inlet, $\mathrm{P}_{\mathrm{o}}$ being the absolute 182 pressure at the outlet, $\rho$ the density of the injected fluid and $\beta$ the inertial coefficient. 183 Forchheimer's law has been experimentally validated and has found some theoretical 184 justifications [33-37].

186 The compressibility of the injected fluid is often neglected by the standard permeability 187 measurements used in casting. However, $Q_{\mathrm{v}}$ is not constant throughout the porous medium 188 when injecting compressible fluids, so Eq. 3 needs to be re-written in terms of mass flow rate $189 \mathrm{Q}_{\mathrm{m}}$ :

190

$$
\bar{\rho} S \nabla P=\frac{\mu}{K} Q_{m}+\frac{\beta}{S} Q_{m}^{2}
$$

191 where $\bar{\rho}$ is the average density of the fluid in the porous medium and $Q_{m}=\bar{\rho} Q_{v}$. For the sake of simplicity, the left term of Eq. 4 will be named $\mathrm{f}(\mathrm{f}=\bar{\rho} \mathrm{S} \nabla \mathrm{P})$. If isothermal flow is assumed and the compressible fluid is considered to be an ideal gas, the following relationship can be used:

$$
\frac{\mathrm{P}}{\rho}=\frac{\mathrm{rT}}{\mathrm{M}}
$$


$\mathrm{F}_{\mathrm{o}}=\frac{\Delta \mathrm{P}_{\text {inertial }}}{\Delta \mathrm{P}_{\text {viscous }}}=\frac{\Delta \mathrm{P}_{\text {total }}-\Delta \mathrm{P}_{\text {viscous }}}{\Delta \mathrm{P}_{\text {viscous }}}=\frac{\Delta \mathrm{P}_{\text {total }}}{\frac{\mu \mathrm{Q}_{\mathrm{m}} \mathrm{L}}{\mathrm{K} \overline{\mathrm{S}}}}-1$

with $\bar{P}$ being the average pressure of the gas throughout the sample.

The criteria for transition from Darcian to non-Darcian flow regimes are commonly given in terms of the non-dimensional Reynolds number Re. However, as discussed by researchers [38], the definition of Re in granular unconsolidated porous media as casting sand is controversial. This is due to the diverse characteristic lengths used in the definition of Re by different authors: average grain size, pore constriction size, the square root of permeability, etc. The latter authors showed that the use of Forchheimer number $F_{0}$ is more suitable for establishing the transition between creeping and inertial flows. $\mathrm{F}_{\mathrm{o}}$ represents the ratio between inertial and viscous pressure drops and is defined from Eq. 3 as follows: 


$$
\mathrm{K}_{\mathrm{app}}=\frac{\mu \mathrm{Q}_{\mathrm{m}}}{\bar{\rho} \mathrm{S} \nabla \mathrm{P}}
$$

\subsection{Materials}

The preceding definition can be derived from Eq. 8 , by using $\beta=0$. Therefore, the inertial effects are not encompassed in $\mathrm{K}_{\mathrm{app}}$ and it is expected to markedly differ from $\mathrm{K}$ at moderate and high-pressure gradients. Standard permeability-characterization methods are based on the measurement of $\mathrm{K}_{\mathrm{app}}$. This explains that these methods are extremely inaccurate unless the flow rate used during the unique measurement is not meticulously selected, as will be shown in subsection 4.3. Indeed, $\mathrm{K}_{\mathrm{app}} \sim \mathrm{K}$ only at low flow rates $\left(\mathrm{F}_{\mathrm{o}}<1\right)$.

\section{Experimental setup and methods}


The raw materials used in the present experiments were quartz silica sand and a furfurylalcohol-based binder (furan resin) of density (1.1-1.2) $\mathrm{g} / \mathrm{cm}^{3}$. The silica sand grains had regular spherical shape, with a mean diameter of $140 \mu \mathrm{m}$ and a standard deviation of $25 \mu \mathrm{m}$, which corresponds to American Foundry Society (AFS) size number 97. The furan binder was a mixture of furfuryl alcohol (70-90 wt \%), bisphenol A (5-15 wt \%), resorcinol (1-10 wt \%) and 3-aminopropyltriethoxysilane $(0.1-0.2 \mathrm{wt} \%)$ [39].

\subsection{Printing stage}

The specimens were first designed with the commercial software NetFabb ${ }^{\mathrm{TM}}$ [40], and were then converted to .stl format. The bar specimens for 3 PB test were designed with length 172 $\mathrm{mm}$, breadth $22.4 \mathrm{~mm}$ and height $22.4 \mathrm{~mm}$. And the cylindrical specimens for permeability test were designed with diameter $=35 \mathrm{~mm}$ and height $75 \mathrm{~mm}$. The dimensions chosen were according to the requirement by the machine for experimental testing of 3DP specimen. Then, the samples were 3D-printed by means of an ExOne S-Print Furan machine [41], with a job-box size of $800 \times 500 \times 400 \mathrm{~mm}^{3}$. The printing process began by mixing sulfonic acid (0.18 wt\% of the sand) catalyst with $8 \mathrm{~kg}$ of silica sand grains inside the mixing chamber of the 3D printer. The mixture was subsequently transferred to the re-coater. Successive layers of 280- $\mu \mathrm{m}$ thickness (i.e. 2 times the mean diameter of the sand grains) were spread over the build platform and a compacting force was applied over the sand bed by means of a re-coater head. Then, the print head nozzle injected the furfuryl alcohol binder on top of these sand layers to bind them. As the droplets of furan resin binder were injected over the layer of acidactivated silica sand bed, a coating layer was formed on top of each individual sand grain. The surface of this resin-bonded sand grains crosslink with each other, forming a bridge of resin 
binder between the sand particles formed by capillarity and gravitational forces immediately after application of the binder. Then, and a hardening mechanism progressively occurs during curing, making the sand particles bond closer as a result of surface tension and forming a strong resin binder-particle bridge. The process continued until the last slice of the sample was printed and the final two sand layers spread.

Previous experiments were performed to evaluate the effect of printing speed on the quality and part integrity [42]. It was concluded that an increased printing speed would influence not only the dimensional accuracy but also the mechanical strength of the 3DP parts due to enhanced inertia forces. It is to be noted that a higher recoating speed also leads to nonuniform spreading of sand over the job-box and low compaction of sand bed, generating lower packing densities and high porosities. On the other hand, it is known that low recoating speed leads to high sand packing density, and consequently to greater flexural strength [43]. The recommended process parameters for minimal variation in 3PB strength and permeability along the job-box were selected according to Ref. $[9,10,44]$ and are listed in Table 1 . The recoating speed was kept constant throughout the printing process and only the printing resolution (furan drop spacing) was altered to achieve different binder percentages. It was highlighted in previous works that loose sand does not provide a good support for the 3D printed parts to build higher up in volume, and results in specimen sinking over the powder bed during compaction [45-47]. Therefore, the specimens were printed over a thick sand layer of $1.4 \mathrm{~mm}$ (around ten layers of sand) in order to avoid sinking, sub-layer displacements [45] and sticking of the resin-bonded sand to the job-box.

A total of $180(60 \times 3$ different binder content $)$ cylindrical specimens were printed for permeability tests. Also, $90(30 \times 3$ different binder content $)$ rectangular bars were printed for 
the 3 PB tests and $(6 \times 3$ different binder content $) 18$ specimens were produced for loss on ignition (LOI) tests. The initial dimensions of the 3D printed parts (bars) were measured using a Vernier caliper, with length, breadth and height of $22.3 \pm 0.02 \mathrm{~mm}, 22.2 \pm 0.02 \mathrm{~mm}$ and $171.9 \pm 0.07 \mathrm{~mm}$, respectively (the uncertainty corresponds to $95 \%$ confidence interval). The initial dimensions of the 3D printed parts (cylinders) were also measured using a Vernier caliper, with length of $74.9 \pm 0.01 \mathrm{~mm}$ and diameter of $34.8 \pm 0.02 \mathrm{~mm}$ with $95 \%$ confidence interval. The temperature of the printing room was $25 \pm 3{ }^{\circ} \mathrm{C}$ and the relative humidity $40 \pm$ $10 \%$. After printing, the samples were then de-powdered, cleaned and taken out of the jobbox.

To go further, Scanning electron microscope (SEM) images were obtained using 3DP specimens of $5 \mathrm{~mm}$ in diameter and height, to verify the furan resin bridges between sand particles. SEM images were obtained with a scanning electron microscope JEOL JSM-7001F. Micrographs of 3DP samples were obtained in low vacuum (0 - $40 \mathrm{~Pa})$ with an acceleration voltage of $5 \mathrm{kV}$ at a $100 \mu \mathrm{m}$ working distance for different magnifications. The scans were acquired and the obtained images were subsequently analyzed and processed using median filter with the open-source platform for image analysis Fiji-ImageJ [48], in order to differentiate between the sand particles, the pores, and the furan resin bridges. Samples of SEM images are presented in Figure 1, showing the morphology of the furan resin bridges within a cross-section of the 3D printed sample.

\subsection{Curing stages}


Despite providing superior mechanical strength to the 3DP parts, high binder amounts can 306 also generate a decrease in permeability, as the pores get filled with liquid. Also, more binder

After the pre-curing stage $25^{\circ} \mathrm{C}, 100{ }^{\circ} \mathrm{C}$ and $200{ }^{\circ} \mathrm{C}$ were chosen as curing temperatures to investigate the curing mechanisms. The choice of these temperatures is motivated by the boiling points at room conditions of water and furfuryl alcohol, which are $100{ }^{\circ} \mathrm{C}$ and $180{ }^{\circ} \mathrm{C}$, respectively. Three curing times were considered: $0 \mathrm{~h}, 2 \mathrm{~h}$, and $14 \mathrm{~h}$. Here the $0 \mathrm{~h}$ conditions represents the initial conditions of the specimen after printing. As observed in the previous work [10], there is a rapid change in $3 \mathrm{DP}$ mold properties after $2 \mathrm{~h}$ curing and approach a constant value after $12 \mathrm{~h}$. Therefore, $0 \mathrm{~h}, 2 \mathrm{~h}$, and $14 \mathrm{~h}$ were chosen for the experiments. Images of a set of heat-treated specimens are shown in Figure 2. One may note that the color of the samples evolves during curing due to the progressive evaporation of binder and water. The binder content, curing times and curing temperatures of the printed samples are listed in Table 2.

\subsection{Loss on Ignition tests}


The Loss-On-Ignition (LOI) test is used to measure the amount of volatile materials present in

330 a sample. In the case of the investigated 3DP sand samples, it was used to measure the mass of binder, i.e. the combined mass of water, resin, catalyst, and volatile impurities. To do so, the initial mass of the printed specimens was first measured, obtaining values close to $30 \mathrm{~g}$ (initial mass) in all cases. The specimens were then put into ceramic crucibles which had been pre-heated at $100{ }^{\circ} \mathrm{C}$ for $1 \mathrm{~h}$ in an oven to extract moisture and organic residues. Once in the crucibles, the $3 \mathrm{DP}$ specimens were heated at $900{ }^{\circ} \mathrm{C}$ for $45 \mathrm{~min}$ so as to burn-out and expel the binder and moisture. After that, the crucible was removed from the oven and the mass of the burnt-out specimen (final mass) was weighted. Images of the crucibles containing the tested samples at the different stages of the LOI tests are provided in Figure 3. From the results of the LOI, the binder contents of the samples were determined using Eq. 9:

Binder content $=\frac{\text { initial mass }- \text { final mass }}{\text { initial mass }} \times 100 \%$

The remaining binder content at each stage of curing was calculated using this procedure, for all curing temperatures and initial binder contents. 6 repetitions were performed for each different binder specimens during the LOI test in order to estimate the experimental uncertainty of the measurements.

\subsection{Porosity measurements}

The porosity of the samples was determined with the oven-dry method. The particle density was considered as being the density of $\mathrm{SiO}_{2}$-quartz $\left(2648 \mathrm{~kg} \cdot \mathrm{m}^{-3}\right)$, which constitutes $99.1 \%$ of 
the sand used by the printer. A laboratory precision balance was used to weight the printed specimens after drying in a hot-air oven at $105{ }^{\circ} \mathrm{C}$ for 24 hours, and the bulk density of the 3DP specimen was calculated as the mass of sample per unit bulk volume. It is worth reminding that both the volume of solid and the volume of pores were taken into account for the calculation of bulk density. In contrast, the particle density was equal to the mass of sample per unit volume of silica sand particles. From the bulk density and particle density, the total porosity of the 3DP specimens was calculated as:

Porosity $=1-\frac{\text { mass of the sample after LOI }}{\text { density of silica } \times \text { volume of the sample }}$

The experimentally measured porosity values were close to $50 \%$ for all tested samples, with an estimated standard deviation of $0.2 \%$. 6 repetitions were performed with 6 analogous specimens for each measurement in order to evaluate the uncertainty related to the repeatability of the porosity tests.

\subsection{Three-Point bending tests}

The 3PB strength of the 3DP specimens was determined through destructive tests, as commonly done with traditionally manufactured sand molds. The tests were performed using a universal strength test machine (Simpson-Electrical PFG type) [49]. The bars were fixed to the testing machine by means of two supporting pins separated $150 \mathrm{~mm}$ from each other. The load was applied by a third pin at the mid-length of the 3DP bar, with a load rate of 0.1 MPa.s ${ }^{-1}$, until the specimens broke. The maximum load capacity of the machine was 12.8 $\mathrm{MPa}$ and the uncertainty of the pressure gauge was $\pm 0.05 \mathrm{MPa} .4$ repetitions were performed 
with 4 analogous specimens for each measurement in order to assess uncertainty. For each binder, the initial 3PB strength was measured using 4 distinct specimens. And the $0 \mathrm{~h}$ condition for each binder content specimen is same as of their initial 3PB strength for different curing temperature.

\subsection{Permeability tests}

The permeability of the printed samples was measured using the experimental setup shown in Figure 4, (Vinci Technologies ${ }^{\mathrm{TM}}$ perm-meter [50]). The experimental procedure started by inserting the cylindrical 3DP sample into a Viton sleeve and mounting it in a Hassler-type core holder. After that, the core was confined with pressurized oil surrounding the sleeve in order to avoid lateral leaks during flow. This oil was provided by an auxiliary confining pump (Enerpac company). Then, air coming from a pressurized cylinder was continuously injected through the cores at a controlled mass flow rate. A set of steeply increasing values of mass flow rate was imposed by means of two mass flow rate regulators (Brooks Instrument B.V, Accuracy: $\pm 0.7 \%$ of flow rate), with working ranges of $0-1 \mathrm{NL} / \mathrm{min}$ and $0-30 \mathrm{NL} / \mathrm{min}$, respectively. The corresponding steady-state pressure drop $\Delta \mathrm{P}$ between the inlet and the outlet of the core $(\mathrm{L}=75 \mathrm{~mm})$ was measured by a membrane-type differential pressure sensor (DP15 Variable Reluctance Pressure Sensor, Validyne Engineering, Accuracy: $\pm 0.2 \%$ of flow rate). The outgoing air was released to atmospheric pressure, so $\mathrm{P}_{\mathrm{o}}$ was assumed to be $0.1 \mathrm{MPa}$ and $\mathrm{P}_{\mathrm{i}}=\mathrm{P}_{\mathrm{o}}+\Delta \mathrm{P}$. Each measurement was repeated four times in order to evaluate uncertainty related to the repeatability of the pressure. For each binder, the initial permeability was measured using 4 distinct specimens at a low flow rate $(0-1 \mathrm{NL} / \mathrm{min})$ and 4 distinct specimens at a high flow rate $(1-30 \mathrm{NL} / \mathrm{min})$. Therefore the $0 \mathrm{~h}$ condition for each binder 
content specimen is the same as of their initial permeability for different curing temperature. A total of 10 flow rate (low flow rate + high flow rate) vs. pressure drop measurements were performed for each case; covering the mass-flow-rate range from $0.01 \mathrm{Nl} / \mathrm{min}$ to $10 \mathrm{Nl} / \mathrm{min}$. The temperature of the core-holder was maintained at $23.0 \pm 2{ }^{\circ} \mathrm{C}$ by using a temperature control subsystem consisting of an electric heating thermostat. The dynamic shear viscosity of air at this temperature was taken as $1.81 \times 10^{-5} \mathrm{~Pa} \mathrm{~s}$. 4 repetitions were performed with 4 analogous specimens for each measurement in order to evaluate the uncertainty related to the repeatability of the tests.

\section{Results and discussion}

The effects of binder content on mass loss, permeability, and 3PB strength for uncured and cured samples were experimentally investigated from the results of the measurements presented in the preceding section.

\subsection{Evolution of binder content during curing as a function of the initial binder content}

The mass loss during curing, as measured by the LOI tests, are represented as a function of curing time and temperature in Figure 5 for the three different values of binder content. All the testing results were the mean value of six measurements. It is noted that loss of binder mass by evaporation was negligible at the room temperature of $25{ }^{\circ} \mathrm{C}$, even after $14 \mathrm{~h}$ of curing. This was expected given that $25^{\circ} \mathrm{C}$ is far below the boiling temperatures of the water 
and alcohols present in the binder. In contrast, a significant decrease in the mass of binder is observed for the three initial values of binder content at both $100{ }^{\circ} \mathrm{C}$ and $200{ }^{\circ} \mathrm{C}$. This decrease is more pronounced within the first two hours of curing.

It is reminded that the furan binder (FNB) is a mixture of furfuryl alcohol and acid catalyst [51]. FNB's condensation reaction produces water, which tends to slow down the rate of curing (dehydration) affecting the mechanical properties of the 3DP mold [13,14]. A closer look to Figure 5 reveals that the rate of mass loss when during curing at $200{ }^{\circ} \mathrm{C}$ is roughly similar to the one at $100{ }^{\circ} \mathrm{C}$, leading to analogous values of remaining binder content after $2 \mathrm{~h}$ and $12 \mathrm{~h}$ in both cases. One may expect a higher evaporation rate at $200{ }^{\circ} \mathrm{C}$, as this temperature is greater than the boiling temperature of both alcohol and water. However, it must be borne in mind that water is released only after polycondensation, which is conditioned by the reaction of the acid catalyst with alcohol. Consequently, less water should be released at $200{ }^{\circ} \mathrm{C}$ as the polycondensation reaction is interrupted by the early evaporation of alcohol. Therefore, it can be concluded from Fig. 8 that the mass of water being evaporated at $100{ }^{\circ} \mathrm{C}$ is equivalent to the sum of the masses of water and alcohol being evaporated at 200 ${ }^{\circ} \mathrm{C}$.

\subsection{PB strength as a function of the initial binder content for different curing conditions}

Figure 6 shows the 3PB strength test results of 3DP sand specimens in the uncured and cured conditions. All the testing results were the mean value of four measurements. It was found 
that 3PB strength increases with binder content for all curing times and temperatures.

Moreover, 3PB strength increases when curing at $100{ }^{\circ} \mathrm{C}$ and decreases when cured at $200{ }^{\circ} \mathrm{C}$

for all binder contents. When curing at $100^{\circ} \mathrm{C}$, the $3 \mathrm{~PB}$ strength experienced an increase of $20 \%$ for $1.02 \%$ binder, $16.7 \%$ for $1.46 \%$ binder and $28 \%$ for $1.98 \%$ binder. However, when curing at $200{ }^{\circ} \mathrm{C}$, the $3 \mathrm{~PB}$ strength experienced a decrease of $41.6 \%$ for $1.02 \%$ binder, $40 \%$ for $1.46 \%$ binder and $22 \%$ for $1.98 \%$ binder.

It is of crucial importance to manufacture 3DP sand molds meeting the requirements in terms of gas evolution during metal casting (low binder content) and optimum 3PB strength. In this regard, 3PB strength should be above 1.5 MPa so that the mold can resist the impact of liquid metal. Therefore, $1.46 \mathrm{wt} \%$ of sand can be selected as the optimum furan resin binder content to print 3DP molds for metal casting with the present technique. Indeed, when the initial furan resin binder content is $1.46 \mathrm{wt} \%$, the $2 \mathrm{~h}$ and $14 \mathrm{~h}$ strengths are above $2 \mathrm{MPa}$, satisfying standard production requirement for casting melted alloy. It is also observed in Figure 6 that 3PB is unaltered by curing at $25{ }^{\circ} \mathrm{C}$. The $3 \mathrm{~PB}$ strength attains its maximum for all binder content when curing at $100{ }^{\circ} \mathrm{C}$ for 2 hours. The reason is that the low roasting temperature $\left(100{ }^{\circ} \mathrm{C}\right)$ provides secondary hardening of furan resin bridges which increases the 3PB strength, while the resin bonding bridges of 3DP sand mold burn at high curing temperature $\left(200{ }^{\circ} \mathrm{C}\right)$, resulting in reduced $3 \mathrm{~PB}$ strength.

The 3PB strength of 3DP sand mold has a direct influence on the strength of the furan resin bridge between sand grains in the sample (adhesion of binder between sand and cohesion of the furan resin binder). This furan resin bridge is formed by capillary action after the binder is dropped by the print head (X-resolution) and strengthens gradually. The intermolecular resin 
bond strength depends on the physical state of the binder and its interaction with the surrounding sand particles. When the 3DP specimen is cured, the furan resin binder hardens by polycondensation (polymerization and condensation), forming a network furan resin bridges which hold the sand particles together. The strength of the resin bridge greatly depends on the amount of the binder content. The volume of the bridge corresponds to the printed furan binder content minus the evaporated solvent (mixture water and alcohol). This resin bridge strengthens gradually and affects the $3 \mathrm{~PB}$ strength of the sample. The strength increases more rapidly at $100{ }^{\circ} \mathrm{C}$ (cured by heat treatment) than at $25{ }^{\circ} \mathrm{C}$ (cured at room temperature). However, this resin bridge hardening and strengthening mechanism have a limit, leading to reduced strength and loss of ductility for prolonged heating at $100{ }^{\circ} \mathrm{C}$ or when heating at high temperature $\left(200{ }^{\circ} \mathrm{C}\right)$. These results facilitate the choice of the optimum binder content, curing time and temperature to obtain the functional values of 3PB strength.

The mechanical and the mass transport properties of the cohesive granular materials depend on their microscopic structure and their composition. A scheme of the resin-bonded bridges between sand particles with simple cubic compaction density is displayed in Figure 7, where $\mathrm{R}_{\text {sand }}$ is the radius of the silica sand particle and $T_{\text {binder }}$ is the thickness of the furan resin bridge. Considering that the binder is evenly distributed over the sand particles, the thickness of the resin bridge is expected to increase when the binder content is increased. This leads to improved cohesion strength of the bonding bridges and higher 3PB strength, in agreement with the experimental results.

\subsection{Permeability as a function of the initial binder content for different curing conditions}


491 The relationships between $\mathrm{f}(=\bar{\rho} \mathrm{S} \nabla \mathrm{P})$ and $\mathrm{Q}_{\mathrm{m}}$ obtained during permeability measurements for 492 uncured samples with different levels of initial binder content are shown in Figure 8. All the 493 testing results were the mean value of four measurements. It is noted that $\mathrm{f}$ increases nonlinearly with increasing mass flow rate deviating from the linear relationship predicted by Darcy's law (Eq. 3 with $\beta=0$ ). As explained in section 2, Darcy's law is only valid for creeping flow at low Reynolds numbers. Therefore, the non-linear behavior observed in Figure 8 reveals that the flow is no longer creeping at moderate and high mass flow rates and the inertial pressure losses are not negligible. The same figure shows that all $\mathrm{f} v \mathrm{v} . \mathrm{Q}_{\mathrm{m}}$ curves collapse for uncured samples, independently of the binder content. Therefore, similar values of permeability and similar inertial pressure drops are expected for the three investigated binder contents when curing is performed at room temperature $\left(25^{\circ} \mathrm{C}\right)$. The $\mathrm{f}$ vs. $\mathrm{Q}_{\mathrm{m}}$ measurements for all the considered binder contents and curing conditions are represented in Figure 9, showing that the curves also collapse for all curing conditions in the case of $1.02 \%$ and $1.46 \%$ initial binder contents. Indeed, significant differences depending on the curing time and temperature were only observed for $1.98 \%$ initial binder content, which will be interpreted below in terms of permeability variation.

$\mathrm{K}_{\text {app }}$ was calculated using Eq. 8, as traditionally done with the standard permeability characterization methods, for different values of the injection flow rate. The experimentally obtained $\mathrm{Q}_{\mathrm{m}}$ vs. $\mathrm{K}_{\mathrm{app}}$ relationship for uncured samples with different binder contents is presented in Figure 10. These results show that $\mathrm{K}_{\mathrm{app}}$ is monotonically decreasing as $\mathrm{Q}_{\mathrm{m}}$ increases for all the specimens, which is explained by the inertial pressure drops which are not taken into account in the calculation of $\mathrm{K}_{\mathrm{app}}$. Moreover, it is observed that the $\mathrm{K}_{\mathrm{app}}$ tends to a 
constant value within the low flow rates region in which the flow is viscous-dominated and the inertial deviations are negligible. Therefore, $\mathrm{K}_{\mathrm{app}} \sim \mathrm{K}$ at the lowest flow rates and $\mathrm{K}$ was considered to be equal to the plateau value.

Darcy's law (Eq. 3 with $\beta=0$ ) was then fitted to the f vs. $Q_{m}$ measurements obtained during permeability tests, as illustrated in Figure 11a for the uncured $1.02 \%$ binder content sample. Similar results were observed for all considered curing conditions. From this figure, it can be deduced that the flow regime is creeping only at the lowest flow rates in which Darcy's law predictions are accurate. However, the deviations from Darcy's law become larger as $Q_{m}$ is increased due to additional inertial pressure drops. Therefore, it is confirmed that both creeping and inertial flow regimes were covered by a wide range of $Q_{m}$ imposed during the measurements. Furthermore, $F_{o}$ (Eq. 7) was also calculated as a function of $Q_{m}$ so as to quantify the relative importance of the inertial pressure drops, as presented in Figure $11 \mathrm{~b}$. The critical value of $\mathrm{F}_{\mathrm{o}}=0.11$ (10\% of inertial pressure drop) marking the transition from Darcian to non-Darcian flow occurs at $\mathrm{Q}_{\mathrm{m}}$ close to $3 \times 10^{-6} \mathrm{~kg} / \mathrm{s}$. Accordingly, for the given sample dimensions and experimental conditions, it can be concluded that flow rates close to 3 $\times 10^{-6} \mathrm{~kg} / \mathrm{s}$ must be used to characterize permeability in this type of casting sands. Nondimensionalization of this criterion is challenging given the compressibility of the injected fluid and will not be addressed in the present work.

Following the procedure presented above, the permeability of the samples was calculated for all the investigated binder contents, curing times and temperatures. The results are presented in Figure 12. It can be observed that no significant evolution of K over time was obtained for the samples cured at $25^{\circ} \mathrm{C}$. This was expected, given the low evaporation rate at room 
temperature in agreement with previous results [21] and the mass loss measurements presented in Fig. 5. Moreover, the permeability of these samples is very close for all binder contents. This may be explained by the combined effect of two mechanisms with opposed effects on permeability: 1) the generation of thicker resin bridges through polymerization at higher binder amounts tend to separate of the grains, which enhances porosity and permeability; and 2) higher binder amounts lead to a higher saturation of the interstices, resulting in a decrease in permeability. However, these mechanisms need further verification, for example through specifically dedicated X-ray micro-computed tomography $(\mu-\mathrm{CT})$ experiments, which will not be presented here.

It can also be observed in Figure 12 that the permeability of the $1.02 \%$ binder content samples remains roughly constant throughout the $14 \mathrm{~h}$ of curing at the three considered temperatures. This may be explained by the thinness of the liquid layer between the sand grains which produces only a very weak reduction in permeability. Also, the polymerization reaction (transformation of the liquid binder into resin bridges) is expected to conclude earlier than for higher amounts of binder, so the liquid saturation is lower and the effects of remaining alcohol and water evaporation are minimum. A stronger effect of evaporation on permeability is observed at $1.46 \%$ and $1.98 \%$ binder contents, which is potentially due to the higher amount of remaining alcohol and water blocking air flow through the pores. Also, a decrease in permeability is observed after $14 \mathrm{~h}$ of curing, which could be explained by the shrinkage effect produced by the burning of the resin bridges [52]. The permeability attains its maximum in the case of the specimen with the highest binder content when heat-treated at $100^{\circ} \mathrm{C}$ for $2 \mathrm{~h}$. It is to be noted that higher amounts of binder would generate more toxic gas. 


\section{Conclusion}

564 The quality of the parts produced by casting in 3DP molds is strongly conditioned by the

565 careful choice of suitable binder content. Motivated by the vital role of this process parameter,

566 the effects of binder content on the permeability and the mechanical strength of 3DP sand

567 molds has been experimentally evaluated for different curing times and temperatures. The

568 following conclusions are drawn from the present work:

$\checkmark$ Binder content has a profound influence on the 3PB strength of 3DP sand molds. Higher binder amounts lead to increased mechanical strengths. Moderate curing temperatures and times $\left(100{ }^{\circ} \mathrm{C}, 2 \mathrm{~h}\right)$ are recommended in order to optimize 3PB (avoiding degradation of the resin bridges, excessive off-gassing, and hot tearing). curing stage.

Mass-loss measurements performed during LOI tests allow the evaluation of liquid evaporation rates, which can be subsequently used in the analysis of the physical mechanisms governing the changes in permeability and 3PB strength during the

$\checkmark$ The effect of binder content on permeability is not significant when curing at room temperature $\left(25^{\circ} \mathrm{C}\right)$. However, liquid evaporation and binder shrinkage significantly affect permeability. Maximum permeability is attained at the same conditions as the optimum 3PB strength.

$\checkmark$ The porosity of the 3DP sand molds is very high, leading to inertial-dominated flows at moderate values of air flow rate. Consequently, permeability measurements must be performed at sufficiently low injection flow rates in order to achieve creeping flow. 
586 The present experimental results facilitate the characterization of printing process parameters

587 by quantifying the effects of binder content on the functionality of 3DP molds. These criteria 588 are most valuable for the production of casting molds meeting the requirements of aerospace 589 and automotive industries.

590

591

\section{Acknowledgements}

592

593 The assistance during 3D printing of sand specimens by Mr. Jérémie Bourgeois and the 594 collaboration with the LIST laboratory of CEA TECH, are greatly acknowledged. The authors 595 also gratefully acknowledge the contribution of colleagues of Arts et Métiers ParisTech for 596 their technical support.

597

598

599

600 
601

602

603

604

605

606

607

608

609

610

611

612

613

614

615

616

617

618

619

620

621

622

\section{References}

[1] Almaghariz ES, Conner BP, Lenner L, Gullapalli R, Manogharan GP, Lamoncha B, et al. Quantifying the role of part design complexity in using 3d sand printing for molds and cores. Int J Met 2016;10:240-52. doi:10.1007/s40962-016-0027-5.

[2] Almaghariz ES. Determining When to Use 3D Sand Printing : Quantifying the Role of Complexity By Eyad S . Almaghariz A thesis Submitted in Partial Fulfillment of the Requirements for the Degree of Master of Science in the 2015.

[3] Conner BP, Manogharan GP, Martof AN, Rodomsky LM, Rodomsky CM, Jordan DC, et al. Making sense of 3-D printing: Creating a map of additive manufacturing products and services. Addit Manuf 2014;1:64-76. doi:10.1016/j.addma.2014.08.005.

[4] Sachs E, Cima M, Cornie J, Bredt J, Fan A, Lee K, et al. Dimensional Printing: Rapid Tooling and Prototypes Directly from CAD Representation. Solid Free Fabr Symp 1990:27-47. doi:10.1016/S0007-8506(07)61035-X.

[5] Sachs E, Cima M, Cornie J, Brancazio D, Bredt J, Curodeau A, et al. ThreeDimensional Printing: The Physics and Implications of Additive Manufacturing. CIRP Ann - Manuf Technol 1993;42:257-60. doi:10.1016/S0007-8506(07)62438-X.

[6] Bredt JF, Anderson T. Method of three dimensional printing, 1999.

[7] Williams CB. Design and development of layer-based additive manufacturing process for realization of metal parts of designed mesostructure 2008:421.

[8] Upadhyay M, Sivarupan T, El Mansori M. 3D Printing for Rapid Sand Casting - A Review. J Manuf Process 2017;29:211-20. doi:10.1016/j.jmapro.2017.07.017. 
623 [9] Coniglio N, Sivarupan T, El Mansori M. Investigation of process parameter effect on

624

625

626

627

628

629

630

631

632

633

634

635

636

637

638

639

640

641

642

643

644 anisotropic properties of 3D printed sand molds. Int J Adv Manuf Technol 2017:1-11. doi:10.1007/s00170-017-0861-5.

[10] Mitra S, Rodríguez de Castro A, El Mansori M. The effect of ageing process on threepoint bending strength and permeability of 3D printed sand molds. Int J Adv Manuf Technol 2018;97:1241-51. doi:10.1007/s00170-018-2024-8.

[11] Marumoto N, Kashimura H, Yoshida K, Toyoda T, Okane T, Yoshida M. Dynamic measurements of the load on gray cast iron castings and contraction of castings during cooling in furan sand molds. J Mater Process Technol 2016;237:48-54. doi:10.1016/j.jmatprotec.2016.05.012.

[12] Motoyama Y, Inoue Y, Saito G, Yoshida M. A verification of the thermal stress analysis, including the furan sand mold, used to predict the thermal stress in castings. J Mater Process Technol 2013;213:2270-7. doi:10.1016/j.jmatprotec.2013.06.024.

[13] Zeitsch KJJ. The Chemistry and Technology of Furfural and its Many By Products. vol. 13. 2001. doi:10.1016/S1385-8947(00)00182-0.

[14] Quaker T, Company O. Catalyst composition and method for curing furan-based foundry binders-US 4451577 A 1984.

[15] Chang KK, Hutchings DA. Furan no-bake foundry binders and their use. 6593397, 2002.

[16] Wan P, Li LC, Zhang L, Wang WQ. Research on testing method of resin sand high temperature compressive strength. China Foundry 2016;13:335-41. doi:10.1007/s41230-016-6013-y. 
[17] Surekha B, Rao DH, Rao GKM, Vundavilli PR. Design and Development of Knowledge Base Scheme for Chromite-based Resin Bonded Sand Core System. Procedia Mater Sci 2014;6:919-25. doi:10.1016/j.mspro.2014.07.161.

[18] Khandelwal H, Ravi B. Effect of Binder Composition on the Shrinkage of Chemically Bonded Sand Cores. Mater Manuf Process 2015;30:1465-70. doi:10.1080/10426914.2014.994779.

[19] Khandelwal H, Ravi B. Effect of molding parameters on chemically bonded sand mold properties. J Manuf Process 2016;22:127-33. doi:10.1016/j.jmapro.2016.03.007.

[20] Liu F, Yang L, Huang Y, Jiang P, Li G, Jiang W, et al. Performance of resin bonded sand for magnesium alloy casting. J Manuf Process 2017;30:313-9. doi:10.1016/j.jmapro.2017.10.002.

[21] Mckenna N, Singamneni S, Diegel O, Singh D, Neitzert T, George JS, et al. Direct Metal casting through 3D printing: A critical analysis of the mould characteristics. 9th Glob Congr Manuf Manag 2008:12-4.

[22] Snelling D, Kay R, Druschitz A, Williams CB. Mitigating Gas Defects in Castings Produced From 3D Printed Molds. 117th Met. Congr., 2013.

[23] Snelling D, Williams CB, Druschitz AP. A Comparison of Binder Burnout and Mechanical Characteristics of Printed and Chemically Bonded Sand Molds. SFF Symp 2014:197-209.

[24] Simpson. Simpson Permeability Meter PDU-D. vol. 41. 2002.

[25] Klinkenberg LJ. The Permeability of Porous Media To Liquids and Gases. Drilling and Production Practice, New York, 1 January 1941, API-41-200 n.d. 
667 [26] Tanikawa W, Shimamoto T. Klinkenberg effect for gas permeability and its

668

669

670

671

672

673

674

675

676

677

678

679

680

681

682

683

684

685

686

687

688 comparison to water permeability for porous sedimentary rocks. Hydrol Earth Syst Sci Discuss 2006;3:1315-38. doi:10.5194/hessd-3-1315-2006.

[27] Hubbert MK. Darcy's law and the field equations of the flow of underground fluids. vol. 2. 1957. doi:10.1080/02626665709493062.

[28] Schneebeli G. Expériences sur la limite de validité de la loi de Darcy et l'apparition de la turbulence dans un écoulement de filtration. La Houille Blanche 1955:141-9. doi:10.1051/lhb/1955030.

[29] Scheidegger AE. The physics of flow through porous media 1957:236 p.

[30] Chauveteau G, Thirriot CL. Régimes d'écoulement en milieu poreux et limite de la loi de Darcy. La Houille Blanche 1967;2:141-8. doi:10.1051/lhb/1967009.

[31] Miskimins JL, Lopez, H J, Baree RD. Non-Darcy Flow in Hydraulic Fractures: Does It Really Matter? SPE Annu. Tech. Conf. Exhib., Dallas,Texas: Society of Petroleum Engineers; 2005, p. 8.

[32] Forchheimer P. Wasserbewegung durch Boden [Movement of Water through Soil]. Zeitschrift Des Vereins Dtsch Ingenieure 1901;45:1782-8.

[33] Dullien FAL, Azzam MIS. Flow rate-pressure gradient measurements in periodically nonuniform capillary tubes. AIChE J 1973;19:222-9. doi:10.1002/aic.690190204.

[34] Geertsma J. Estimating the Coefficient of Inertial Resistance in Fluid Flow Through Porous Media. Soc Pet Eng J 1974;14:445-50.

[35] Macdonald IF, El-Sayed MS, Mow K, Dullien FAL. Flow through Porous Media-the Ergun Equation Revisited. Ind Eng Chem Fundam 1979;18:199-208. 

doi:10.1021/i160071a001.

690 [36] Rasoloarijaona M, Auriault JL. Nonlinear seepage flow through a rigid porous medium. Eur J Mech - B/Fluids 1991;13:177-95.

692

693

694

695

696

697

698

699

700

701

702

703

704

705

706

707

708

709

710

[37] Javadi M, Sharifzadeh M, Shahriar K, Mitani Y. Critical Reynolds number for nonlinear flow through rough-walled fractures: The role of shear processes. Water Resour Res 2014;50:1789-804. doi:10.1002/2013WR014610.

[38] Zeng Z, Grigg R. A Criterion for Non-Darcy Flow in Porous Media. Transp Porous Media 2006;63:57-69. doi:10.1007/s11242-005-2720-3.

[39] ExOne. FB001 (Furan Binder) - Fiche De Données De Sécurité Caprolactam,selon 1907/2006/CE, Article 31 2014:2-11.

[40] Autodesk Inc. Netfabb® 2017.

[41] ExOne. S-Print ${ }^{\mathrm{TM}}$ Furan. 2014.

[42] Miyanaji H, Momenzadeh N, Yang L. Effect of printing speed on quality of printed parts in Binder Jetting Process. Addit Manuf 2018;20:1-10. doi:10.1016/j.addma.2017.12.008.

[43] Bobby SS. A Preliminary Investigation of Gypsum Bonded Moulds By Three Dimensional Printing. IJRET Int J Res Eng Technol 2014;03:501-7.

[44] Sivarupan T, ElMansori M, Coniglio N. 3D Printing Process Parameters and Properties of Additively Manufactured Sand Mold for Rapid Casting: Strength and Permeability. Addit Manuf 2017:(under review).

[45] Lee JJ, Sachs E, Cima M. Layer position accuracy in powder based rapid prototyping. Rapid Prototyp J 1995;1:24-37. doi:10.1108/13552549510104447. 
[46] Dimitrov D, Beer N. Developing capability profile for the three dimensional printing process. R D J 2006;22:17-25.

[47] D.M. Dimitrov, N. de Beer. IMPROVEMENTS IN THE CAPABILITY PROFILE OF 3-D PRINTING: AN UPDATE. South African J Ind Eng 2014;25:1-12. doi:10.11842/wst.2014.02.015.

[48] Schindelin J, Arganda-Carreras I, Frise E, Kaynig V, Longair M, Pietzsch T, et al. Fiji: An open-source platform for biological-image analysis. Nat Methods 2012;9:676-82. doi:10.1038/nmeth.2019.

[49] Simpson. SIMPSON Universal Strength Machine PFG. vol. 41. 2008.

[50] Vinci Technologies. BENCH TOP PERMEAMETER SYSTEM n.d.

[51] Holtzer M, Dańko R. Molds and Cores Systems in Foundry 2015:27-43. doi:10.1007/978-3-319-14583-9.

[52] Lowe K E, Showman R E. Dimensional Changes in Chemically Bonded Molds and Cores. Trans Am Foundry Soc 2011;119:251-60. 


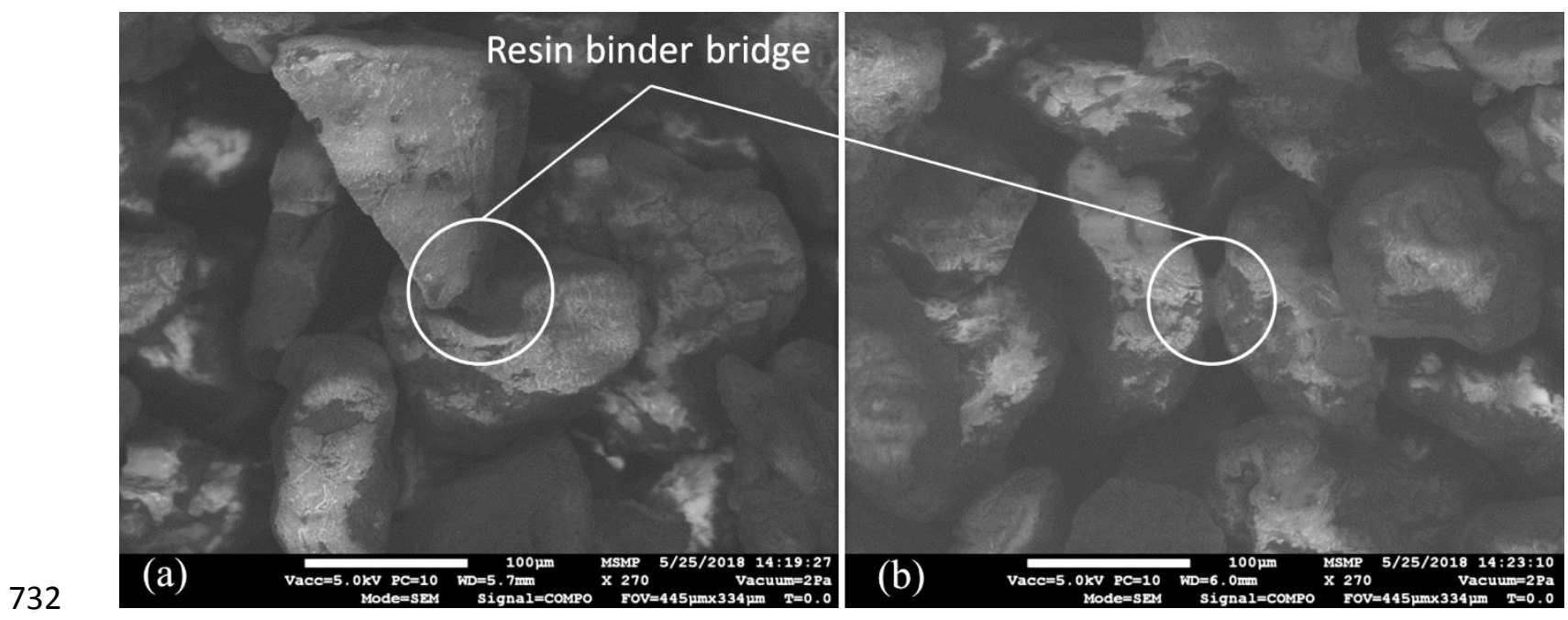

733 Figure 1. Scanning electron microscope (SEM) image of the 3DP sample, (a, b) zoom 734 showing the resin bridges



$$
100^{\circ} \mathrm{C}
$$

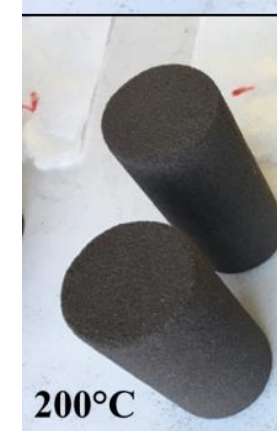

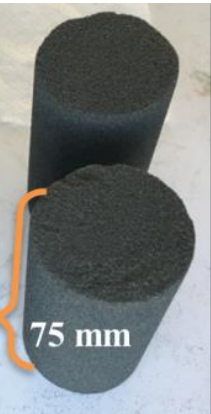

(a)

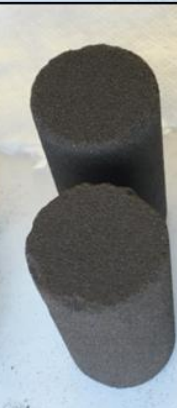

$100^{\circ} \mathrm{C}$

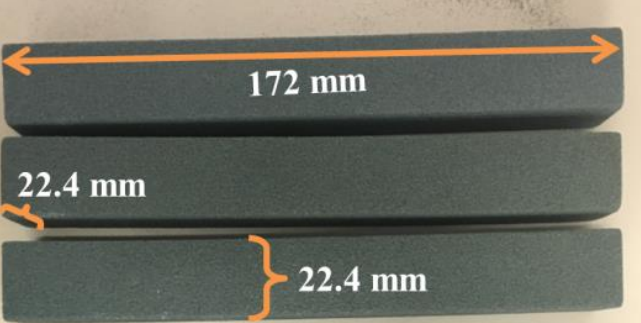

$22.4 \mathrm{~mm}$

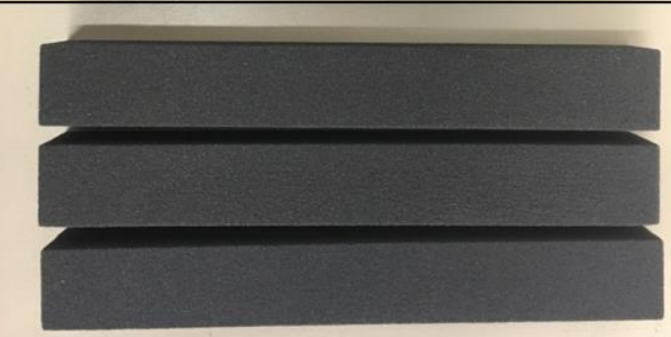

(b) $200^{\circ} \mathrm{C}$ (c)

(d)

Figure 2. Heat-treated 3DP samples with $1.45 \%$ binder, (a,b) cylinders and (c,d) bars 

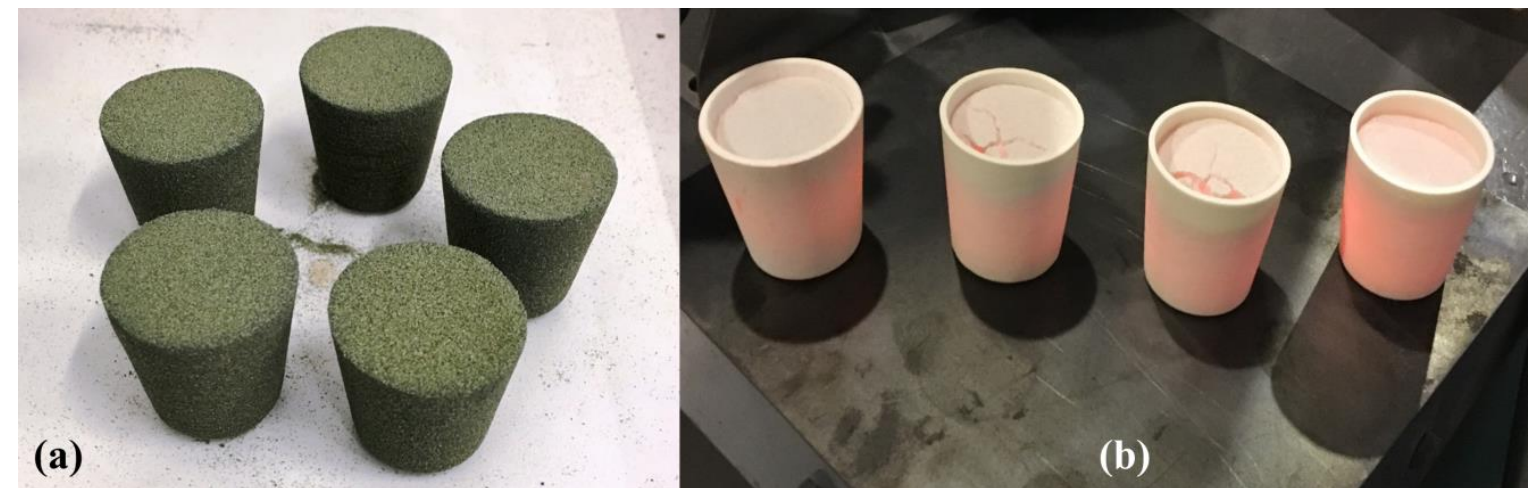

Figure 3: LOI test with (a) 3DP specimens, (b) immediately after taking out of the oven at

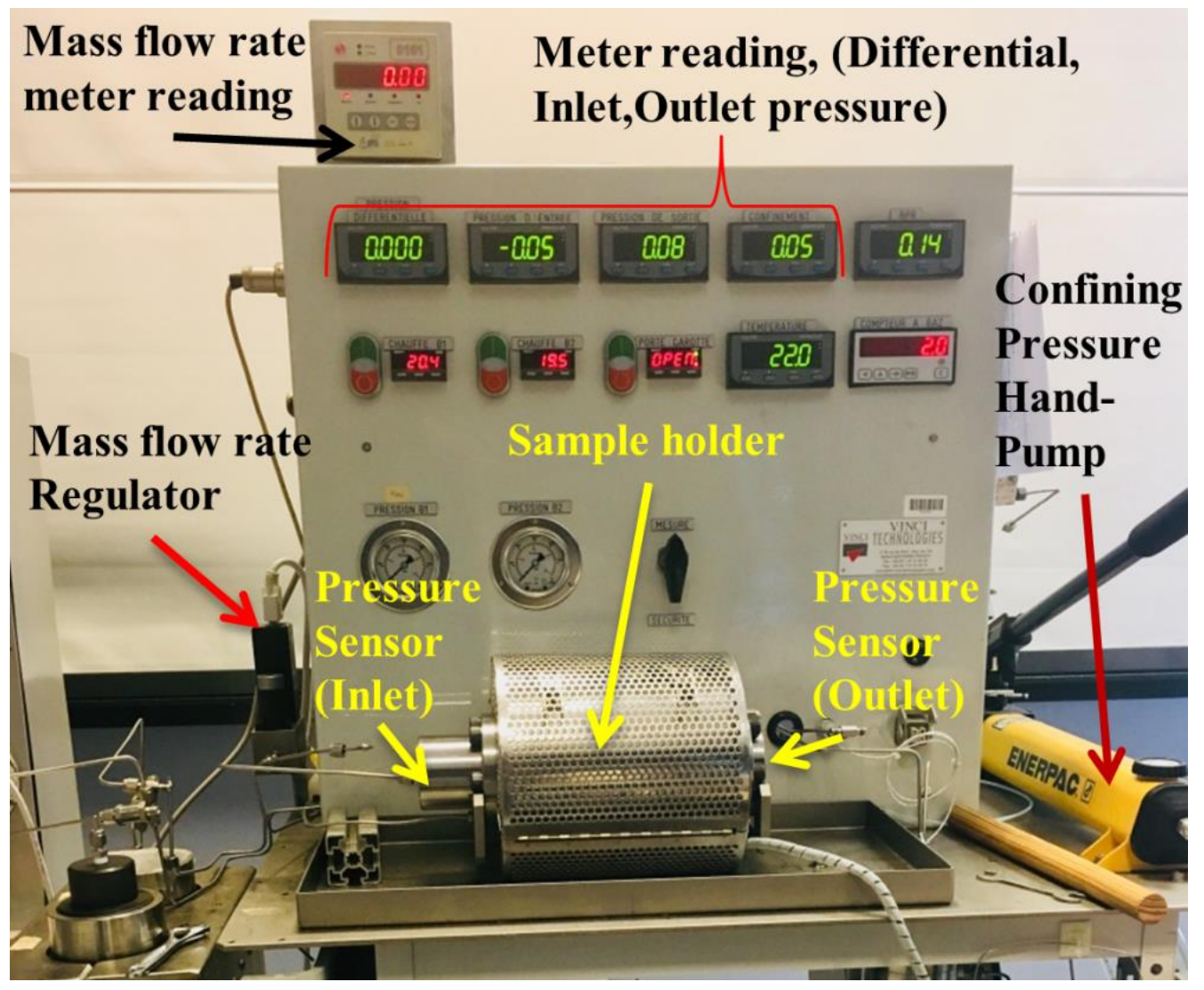



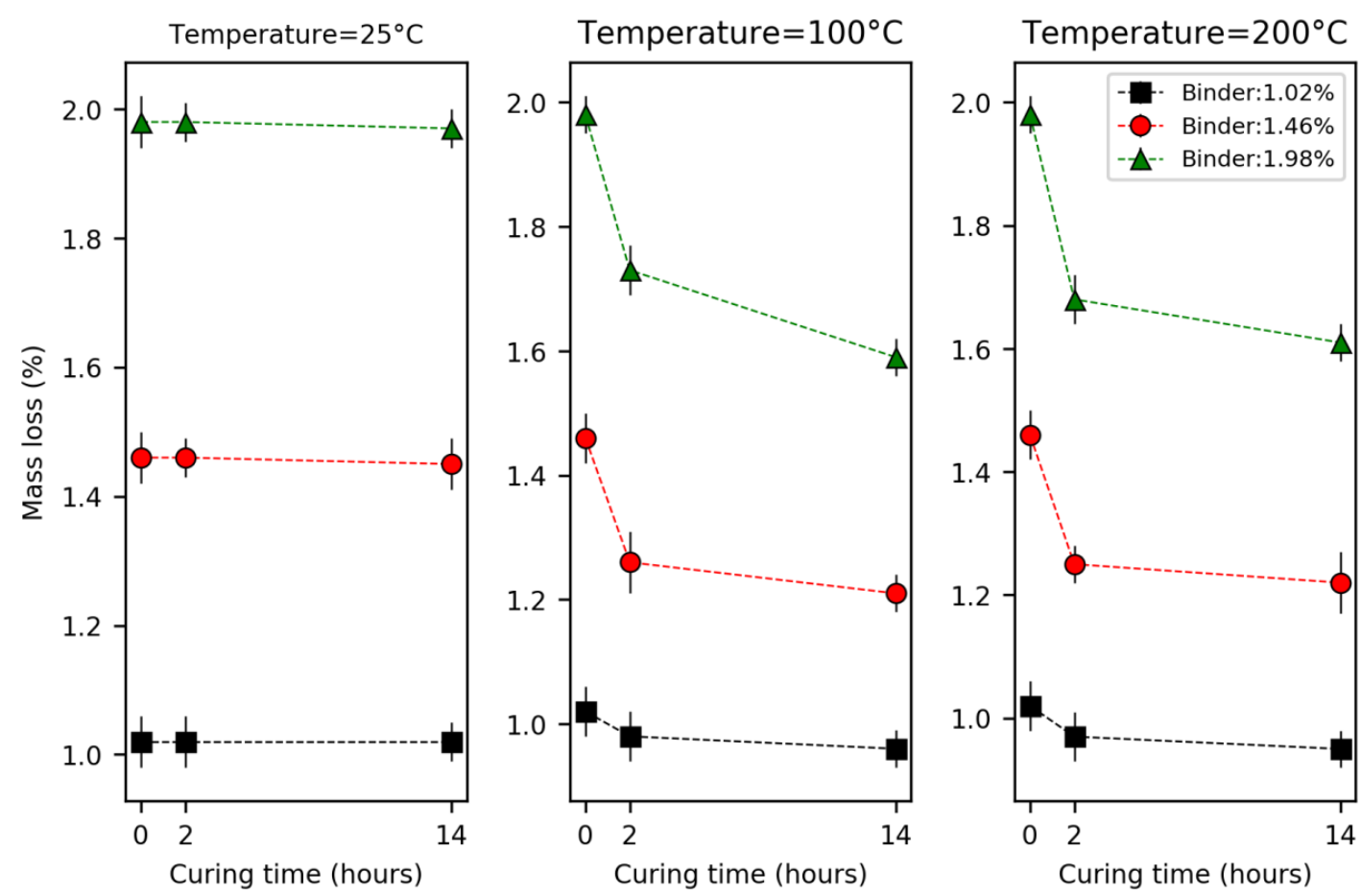

Figure 5. Mass loss as a function of curing time for three curing temperatures


Figure 6. Effect of curing parameters on 3PB strength 


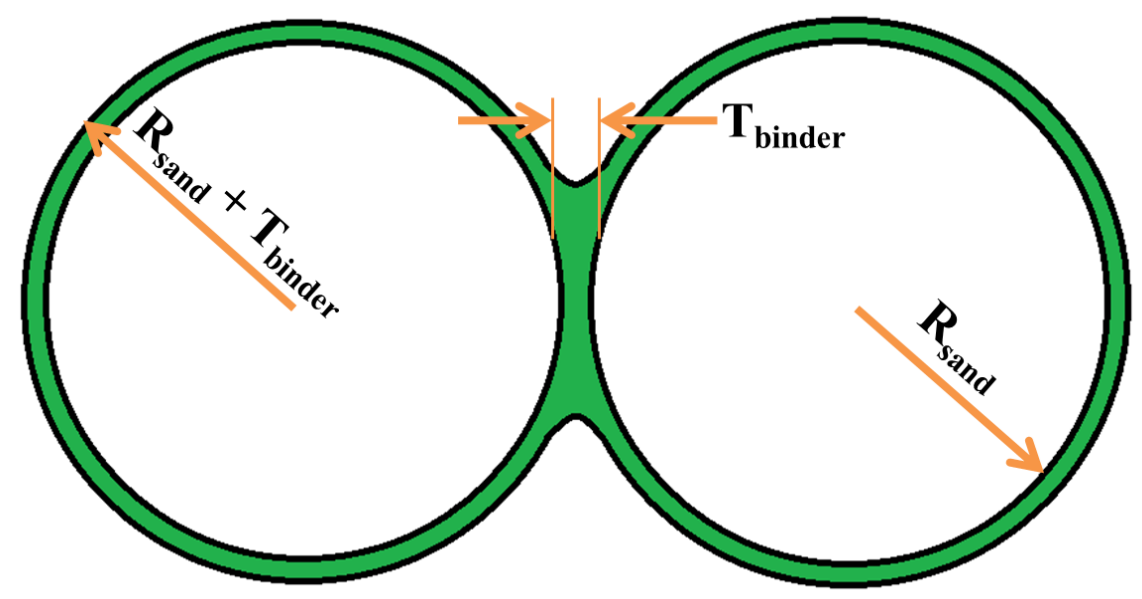

Figure 7. Resin bonding bridge of adjacent sand particles

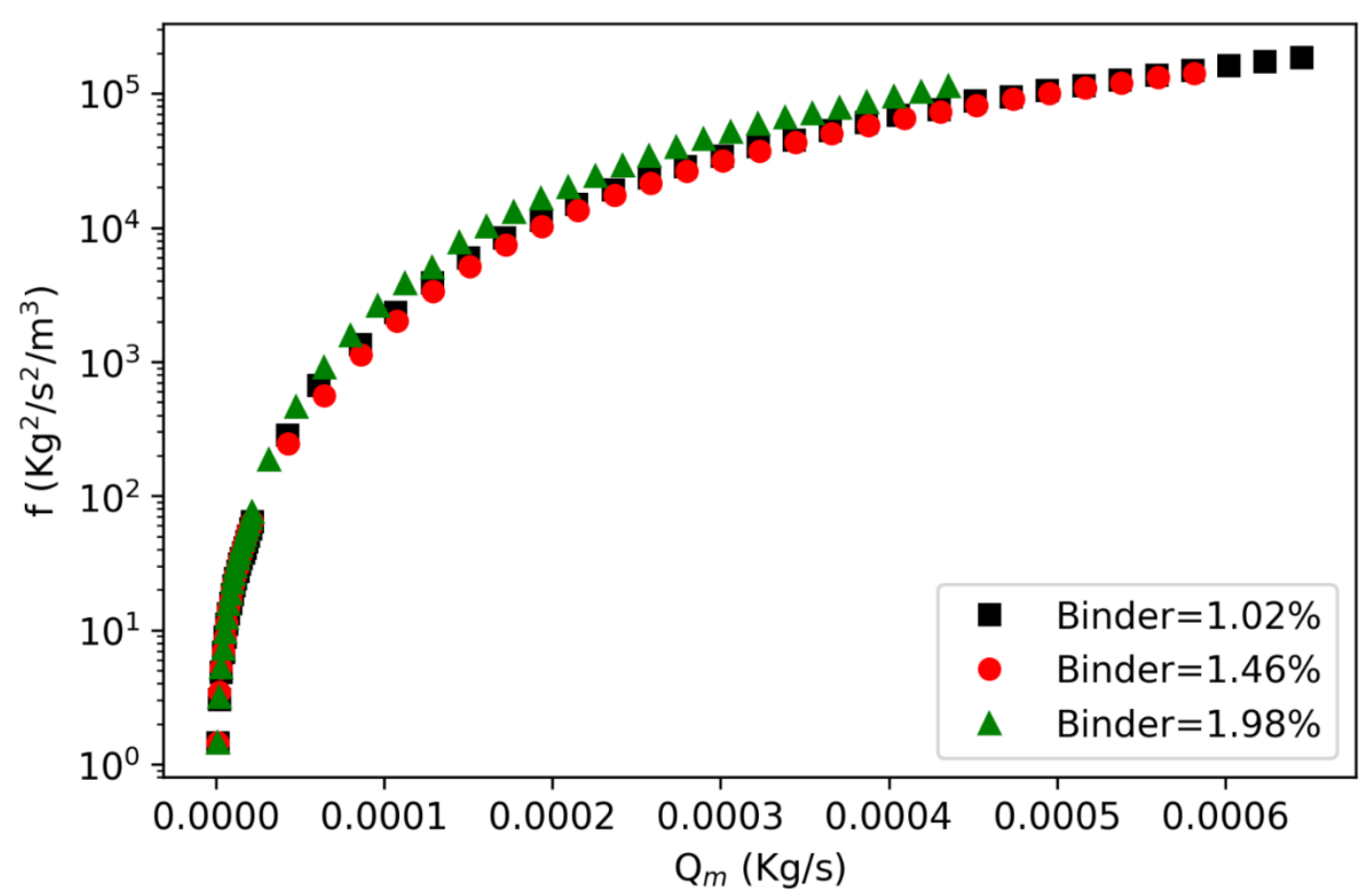

Figure 8. Effect of binder content on $\mathrm{f}$ vs. $\mathrm{Q}_{\mathrm{m}}$ rate for uncured samples at $25^{\circ} \mathrm{C}$. 


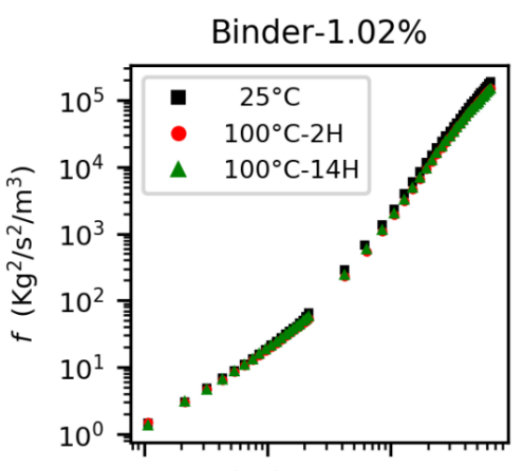

Binder-1.02\%

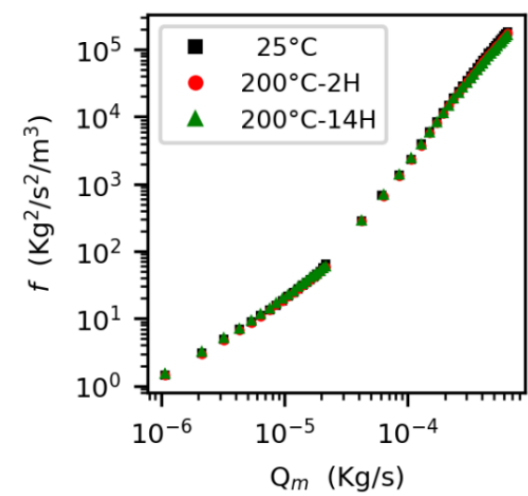

Binder-1.46\%

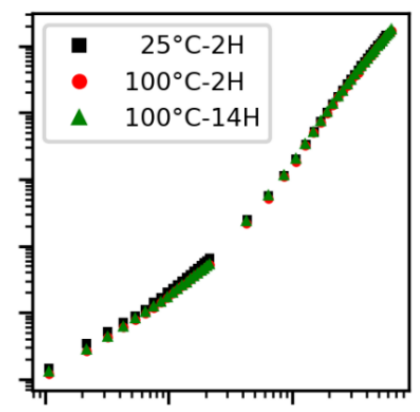

Binder-1.46\%

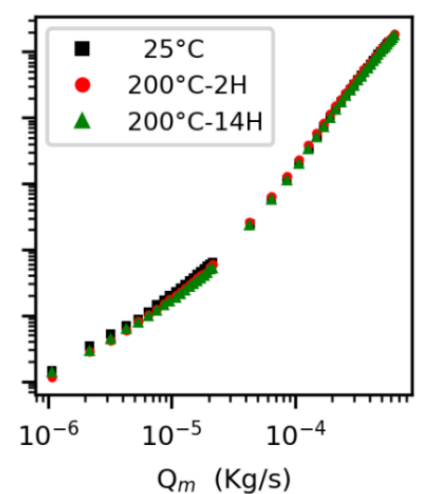

Binder-1.98\%

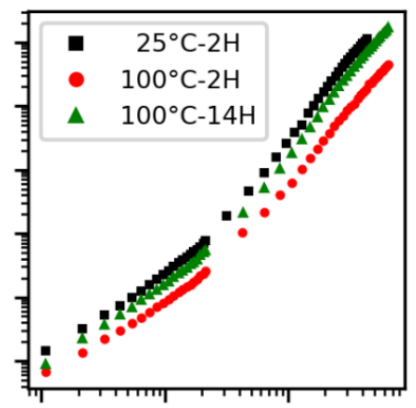

Binder-1.98\%

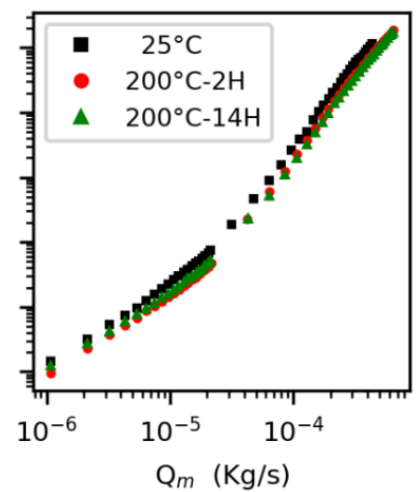

Figure 9. Effect of curing time on the relationship between $f$ and $Q_{m}$ at different temperatures 761 and binder contents

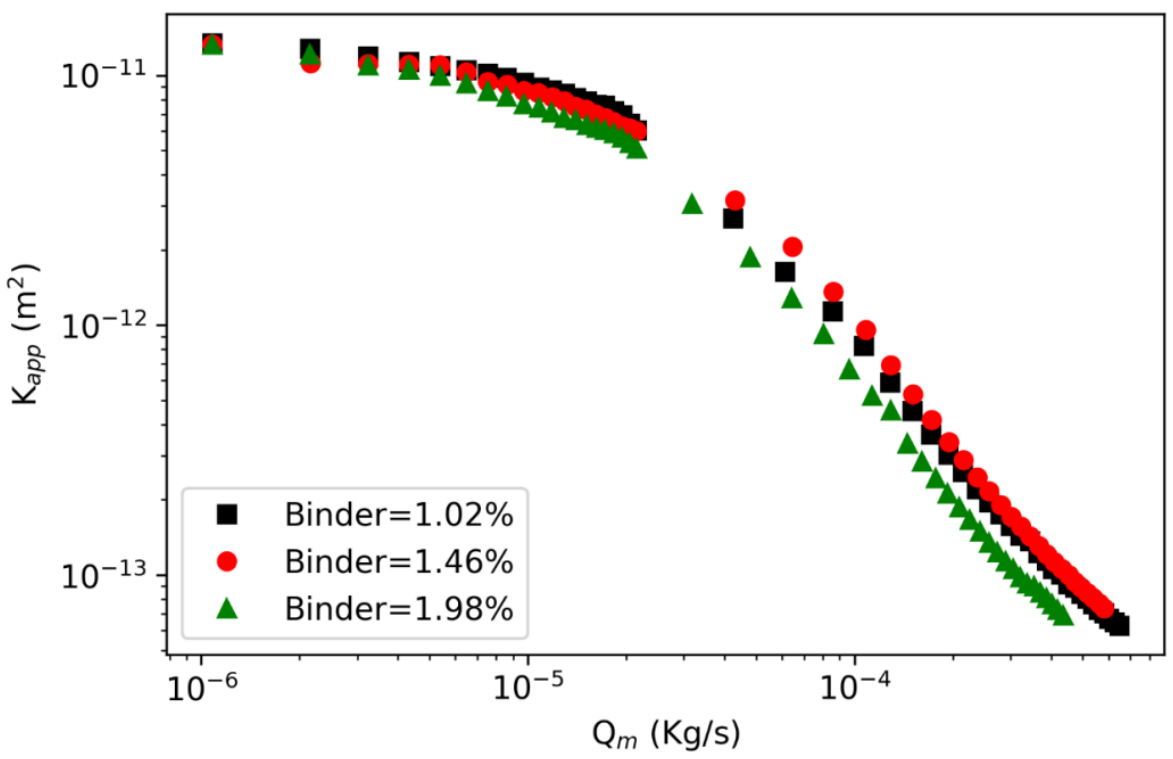

Figure 10. Relationship between apparent permeability and mass flow rate for uncured samples at $25^{\circ} \mathrm{C}$. 
(a)

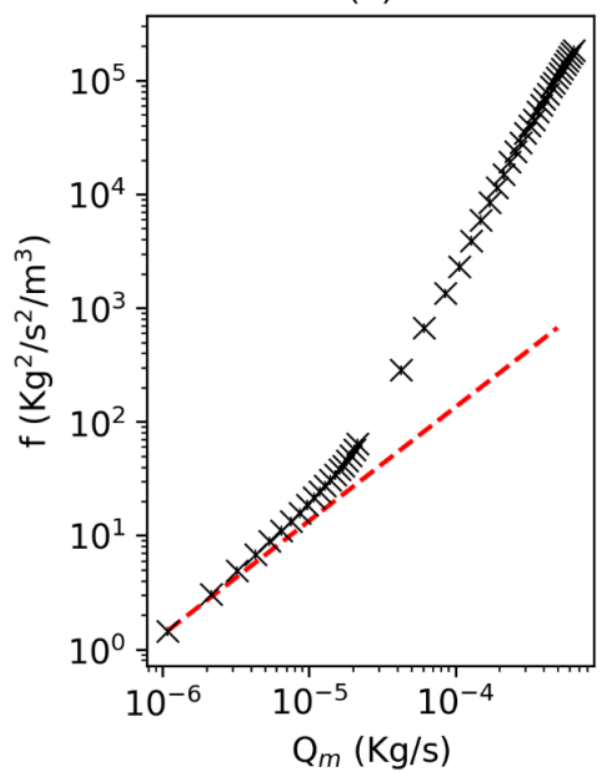

(b)

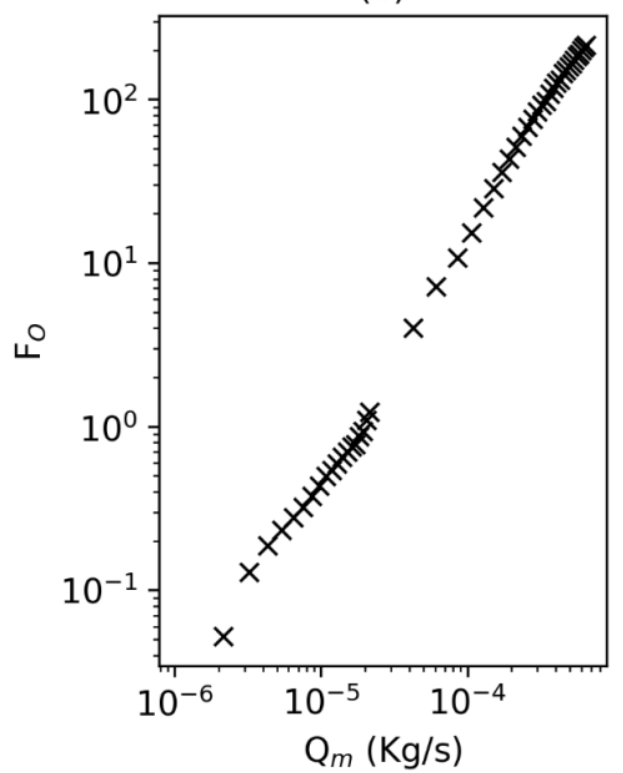

766

Figure 11. Evaluation of the inertial effects for uncured samples at $25^{\circ} \mathrm{C}$ and a binder content of 1.02\%: (a) Darcy's law fit. Black symbols represent experimental measurements. The red dashed line represents Darcy's law fit; (b) Forchheimer number at different flow rates.
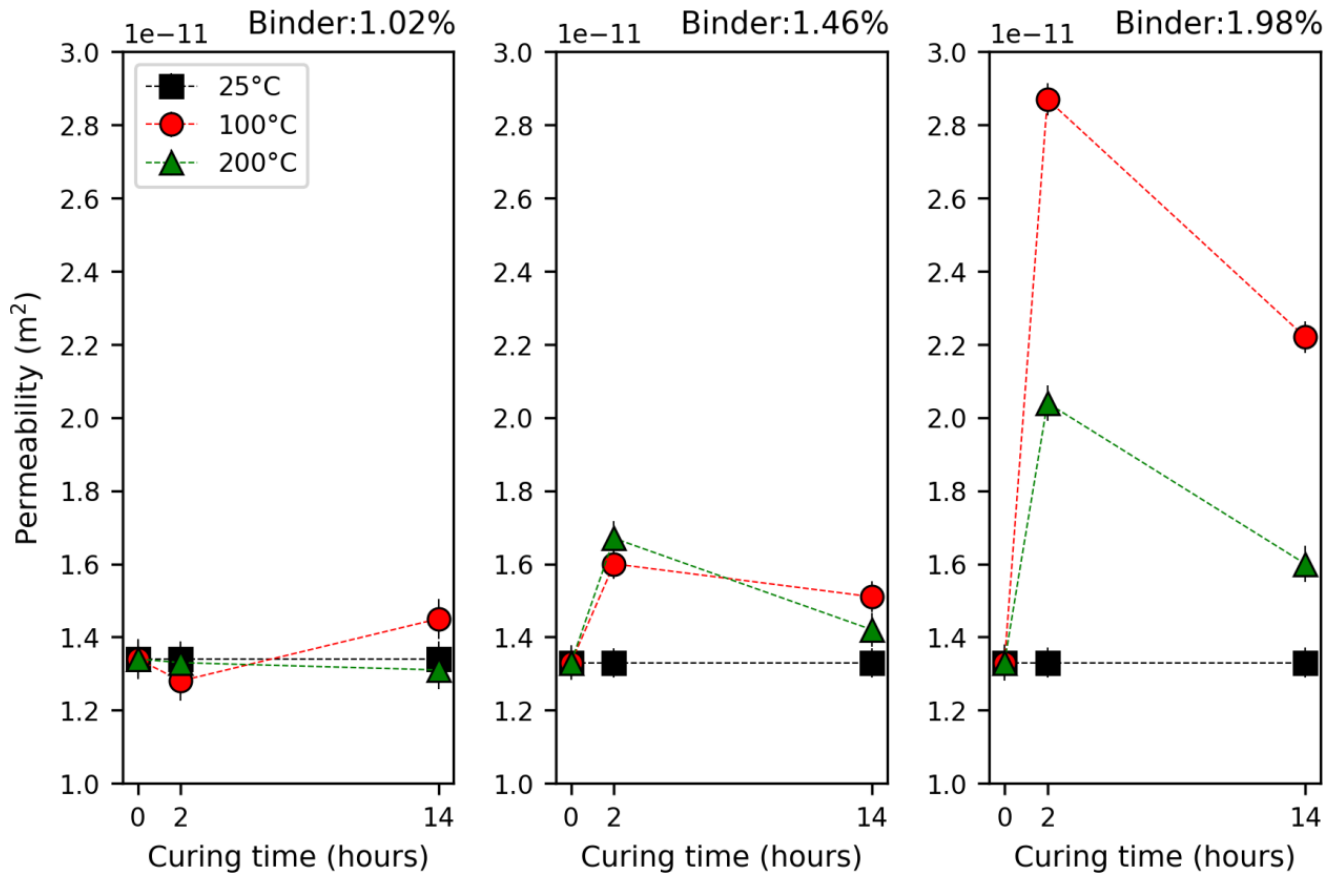

Figure 12. Variation of permeability with binder content, curing temperature and time 


\begin{tabular}{|l|l|}
\hline Average sand grain diameter & $140 \mu \mathrm{m}$ \\
\hline American Foundry Society (AFS) number & 97 \\
\hline Recoating speed & $0.182 \mathrm{~m} / \mathrm{s}(14 \%)$ \\
\hline X Resolution & $80 \mu \mathrm{m}, 120 \mu \mathrm{m}$ and $140 \mu \mathrm{m}$ \\
\hline Y Resolution & $101.6 \mu \mathrm{m}$ \\
\hline Z-resolution/Layer thickness & $280 \mu \mathrm{m}$ \\
\hline Print head voltage & $78 \mathrm{~V}$ \\
\hline Activator content(sulfonic acid) & $0.18 \%$ of the weight of sand \\
\hline Infrared heating temperature & $32^{\circ} \mathrm{C}$ \\
\hline
\end{tabular}

Table 2. Experimental parameters

\begin{tabular}{|c|c|c|c|}
\hline Parameters (Unit) & Category 1 & Category 2 & Category 3 \\
\hline Binder $(\mathrm{wt} \%)$ & $1.02 \pm 0.03$ & $1.46 \pm 0.02$ & $1.98 \pm 0.02$ \\
\hline Curing time (hours) & 2 and 14 & 2 and 14 & 2 and 14 \\
\hline Curing temperature $\left({ }^{\circ} \mathrm{C}\right)$ & 25,100 and 200 & 25,100 and 200 & 25,100 and 200 \\
\hline
\end{tabular}

